\title{
Subretinal fluid application to close a refractory full thickness macular hole
}

\author{
Carsten H. Meyer ${ }^{*}$, Robert Borny and Nicole Horchi
}

\begin{abstract}
Background: To close a refractory full thickness macular hole (FTMH) by adjacent subretinal fluid application to release the elastic retina from the retinal pigment epithelium (RPE).

Case presentation: A 83 years old patient presented an old FTMH with a diameter of $1444 \mu \mathrm{m}$. After confirming intraoperatively the complete release of the epiretinal membrane around the FTMH, we installed 3 small subretinal blebs around the hole, to release the adjacent retina from the RPE. The mobilized retina was gently moved towards the macular center. A silicone oil tamponade was installed to secure a proper healing and observation of the FTMH. The closure of the $1444 \mu \mathrm{m}$ FTMH was seen on indirect ophthalmoscopy and confirmed by OCT 5 days after surgery by restoring the retinal architecture. A late reopening was not apparent at the postoperative observations. Visual acuity improved from hand motion to 20/200 at 4 weeks postoperative.
\end{abstract}

Conclusion: Although FTMH develop by epiretinal tangential traction, large FTMH may persist even after complete release of its epiretinal traction. Subretinal fluid application may release the flexible retina from the RPE to achieve a relocation at the central fovea facilitating an anatomical closure of the macular hole.

\section{Background}

Full thickness macular hole (FTMH) is a defect of all neuroretinal layers at the foveal center. Treatment of FTMH by pars plana vitrectomy (PPV) and consecutive gas tamponade was first described by Kelly and Wendel and has been refined since then, to improve the anatomical functional outcome [1]. The current standard approach treats the underlying epiretinal pathology by removing vitreous adhesions including the internal limiting membrane (ILM) to release tangential traction from the epiretinal surface. An additional intraocular gas tamponade will assist the healing and closure of the macular hole within days. With this approach, most authors report anatomical closure rates greater than $90 \%$, although some MHs fail to close following this approach [2].

Attempts to treat refractory macular holes may include installation of silicone oil, application of autologous platelet concentrates [3] and more recently inverted internal limiting membrane flap application [4] or autologous neurosensory retinal free flap transplantation [5].

*Correspondence: meyer_eye@yahoo.com

Pallas Clinics, Bahnhofplatz 2, 5000 Aarau, Switzerland
Here we present a refractory large macular hole after repeated attempts with ILM peeling and secondary silicone oil installation, which remained open. In this case we used a novel technique by the application of subretinal fluid to shift the released retina towards the center to achieve an anatomical closure of the macular hole.

\section{Case presentation}

A 83 years old patient presented a large sized FTMH in his left eye. Uneventful $\mathrm{ppV}$ with consecutive chromovitrectomy, application of brilliant blue dye (BBD) and consecutive $12 \%$ C2F6 gas application remained unsuccessful. Although the postoperative optical coherence tomography $(\mathrm{OCT})$ defined no residual epiretinal membrane on the retina, the macular hole remained unchanged (horizontal $1444 \mu \mathrm{m}$ vertical $1380 \mu \mathrm{m}$ microns diameter). During reoperation we confirmed this observation by restaining the retinal surface by $B B D$ and determined a negative staining up to the upper and lower arcade. Due to the extensive ILM removal during the first surgery, additional ILM patch transplantation was not feasible in this situation anymore and a silicone oil tamponade was installed for 6 week. However, the macular hole remained 
also unchanged on postoperative OCT and after oil removal (Figs. 1, 2). In a résumé, we discussed with the patient the past procedures and additional published treatment options. In preparation for an additional reoperation we remembered, that our previous application of subretinal fluid during limited macular translocation was capable to shift the entire retina up to $1700 \mu \mathrm{m}$ [6]. Based on this experience with macular translocation we adopted

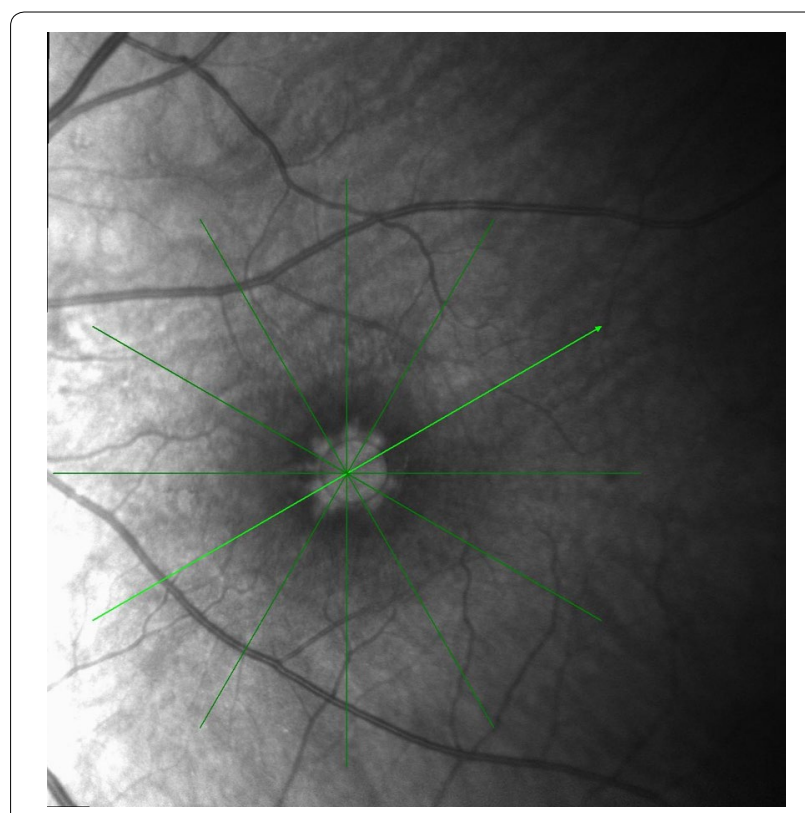

Fig. 1 Fundus photo of the giant macular hole with radial scans, measureing a diameter of 1444-1376 $\mu \mathrm{m}$ this concept for our patient and developed a novel surgical approach for macular hole surgery. The patient agreed and gave informed consent for this procedure.

First, we installed a small decaline bleb over the macular hole to cover the edges of the hole. Next, we carefully applied three small subretinal blebs of 2-3 DD in the superior, temporal and inferior quadrant using a 41-gauge subretinal cannula connected to $1 \mathrm{cc}$ syringe filled with balanced salt solution (BSS). The next step was the removal of the decaline by shifting the bleb over the optic disc and removing it safely. Then we applied BSS fluid at one retinotomy until the subretinal blebs connected to a small perifoveal serous neurosensory detachment. The released paracentral retina was gently massaged towards the foveal center using the Tano diamond dusted scraper.

After fluid air exchange, we installed silicon oil to secure the healing of the sealed macular hole, and to observe the retina during the early postoperative period. Five days after surgery we observed by OCT a closure of the giant macular hole.

Moreover, there was a restoration of the anatomical architecture (Fig. 3) with significant visual acuity improvement to $20 / 200$ postoperatively.

\section{Discussion}

Numerous secondary surgical attempts have been described to achieve a surgical closure of refractory FTMH after successful chromovitrectomy with ILM removal: (a) while restaining the retinal surface may confirm the complete release of the ILM, (b) repeated gas or silicone oil application may enhance the duration of the tamponade and time to close especially large holes. (c)

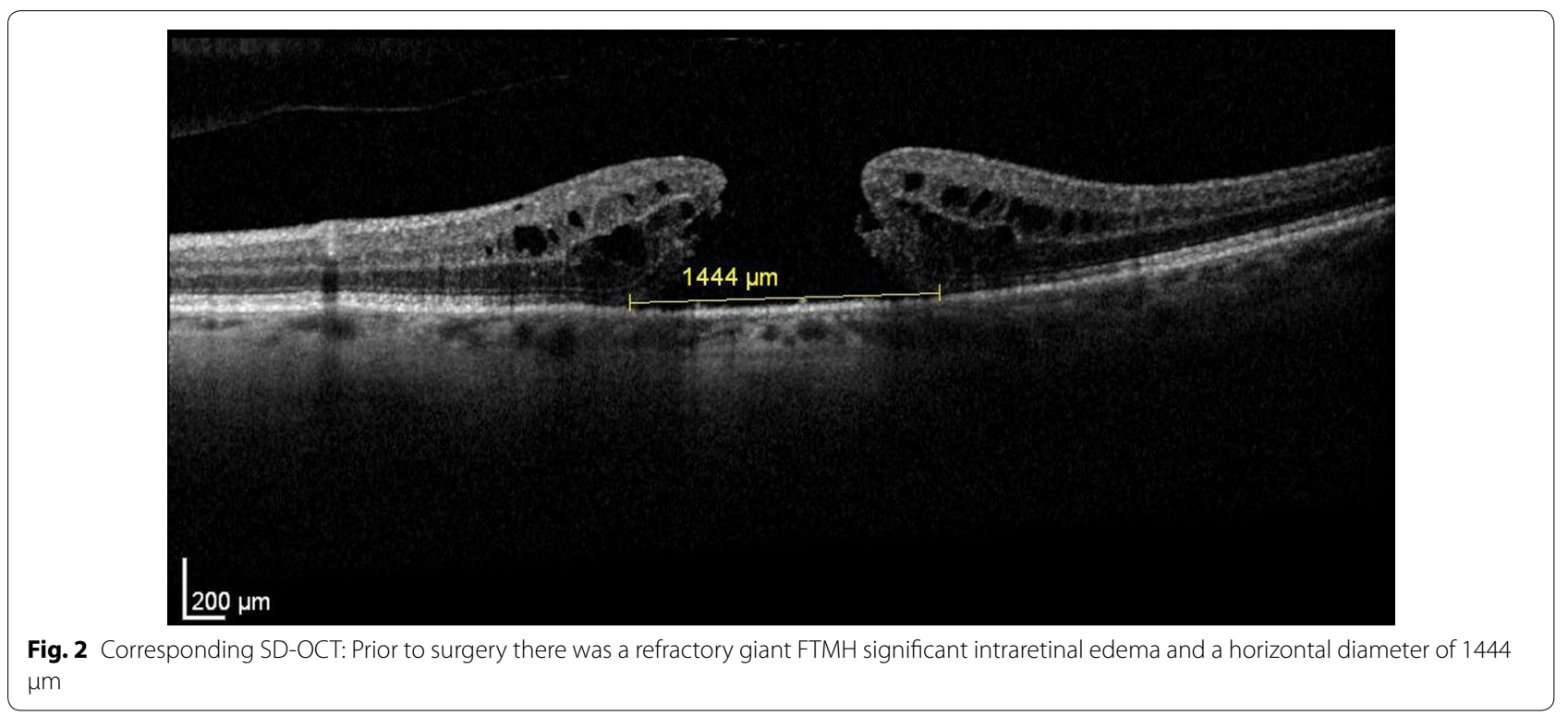




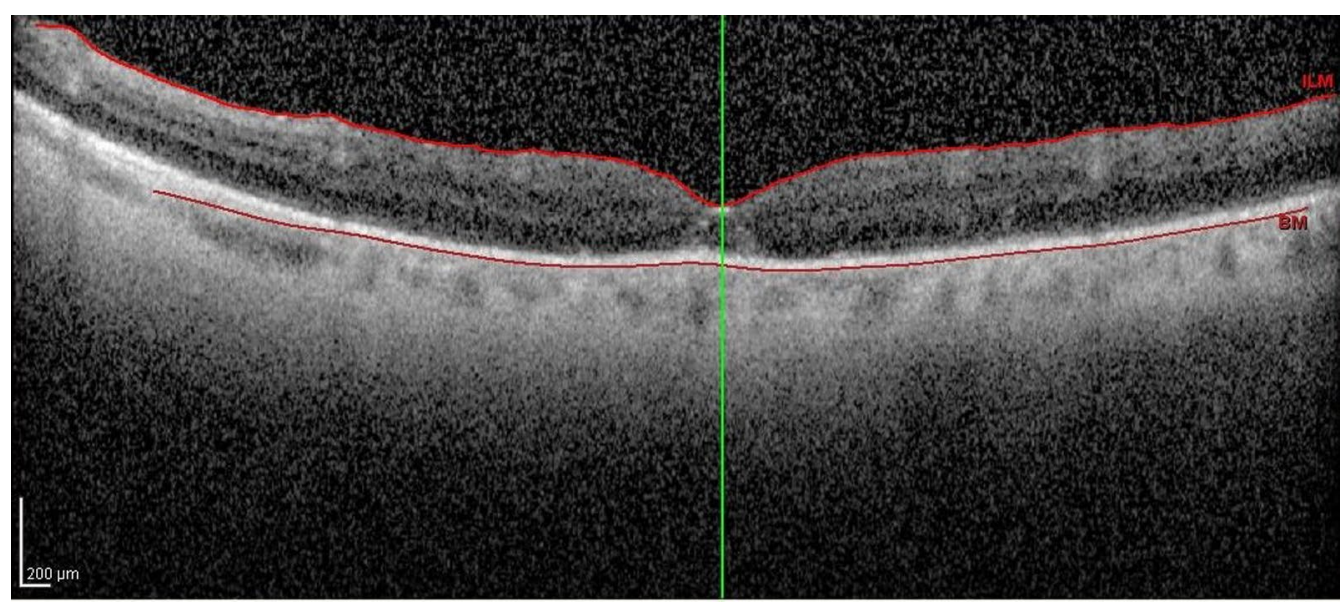

Fig. 3 SD-OCT demonstrated 5 days after surgery the closure of the FTMH and restoration of the anatomical architecture

More recent ILM patches may release growth factors or guide as sheath to the adjacent retina to heal the macular hole [4]. (d) The contraction of the macular hole itself may be enhanced by the cellular force of platelet cell application, or intraoperative aspiration at the edges of the macular hole with some fluid or by a forceps [7]. However, the mechanical or tactile traction may also traumatize the delicate retinal structure limiting the functional outcome and visual acuity. (e) Here we present a novel approach, which involves the induction of a serous macular detachment around the $\mathrm{MH}$ and parafoveal retinal massage to narrow the edges and to achieve an anatomical closure.

We hypothesize, that in giant FTMH not necessarily the release of the tangential traction, but the firm adhesion of the perpendicular photoreceptors to the RPE may prevent a successful closure of the macular hole. In limited macular translocation we learned that the retina may shift by more than $1700 \mu \mathrm{m}$ (range, 680-3200) by creating a serous detachment and scleral imbrication.

Massaging the neurosensory retina with a scrapper is also potentially a traumatic maneuver. Controversly, we discussed if the mechanical brushing of the parafoveal retinal surface with a Tano scraper is essential and required in all cases. An iatrogenic trauma may be induced by the extend of the epiretinal massage. Thus, we proposed in future cases with primary failed larger FTMH closure, to apply solely subretinal fluid with a gas endotamponade in order to close even larger macular holes without secondary mechanical maneuvers.

\section{Conclusion}

A primary release of the centripetal force by the ILM removal, followed by a release of the RPE-photoreceptor adherence may mobilize the elastic retina from epiretinal and subretinal adhesions completely. Secondary, stretching of the retina by application of subretinal fluid and tactile massage may enlarge the retinal surface covering potentially large macular holes. The here presented novel subretinal approach may serve as a first prove of principle to close residual FTMHs after subretinal fluid injection successfully.

\section{Authors' contributions}

CHM performed all surgeries in this patient. $\mathrm{NH}$ and RB performed all pre- and postoperative examinations. All three authors contributed equally to the preparation of the paper. All authors read and approved the final manuscript.

\section{Acknowledgements}

Not applicable.

\section{Competing interests}

The authors declare that they have no competing interests.

Availability of data and materials Not applicable. This is a case report.

\section{Consent for publication}

Written informed consent was obtained from the patient for publication of this Case report and any accompanying images.

\section{Ethics approval and consent to participate}

All the scientific and ethical principles of the Helsinki Declaration on Human Research were respected.

Funding

All the sources were provided by the authors.

\section{Publisher's Note}

Springer Nature remains neutral with regard to jurisdictional claims in published maps and institutional affiliations.

Received: 13 September 2017 Accepted: 25 September 2017

Published online: 27 November 2017 


\section{References}

1. Kelly NE, Wendel RT. Vitreous surgery for idiopathic macular holes. Results of a pilot study. Arch Ophthalmol. 1991;109:654-9.

2. Meyer CH, Schmidt JC, Mennel S, Göddeke E, Rübe K, Rodrigues EB, Kroll P. Anatomical and functional results after macular hole surgery. Klin Monbl Augenheilkd. 2008;225:220-7.

3. Paques M, Chastang C, Mathis A, Sahel J, Massin P, Dosquet C, Korobelnik JF, Le Gargasson JF, Gaudric A. Effect of autologous platelet concentrate in surgery for idiopathic macular hole: results of a multicenter, doublemasked, randomized trial. Platelets in Macular Hole Surgery Group. Ophthalmology. 1999:106:932-8.

4. Michalewska Z, Michalewski J, Adelman RA, Nawrocki J. Inverted internal limiting membrane flap technique for large macular holes. Ophthalmology. 2010;117:2018-25.
5. Grewal DS, Mahmoud TH. Autologous neurosensory retinal free flap for closure of refractory myopic macular holes. JAMA Ophthalmol. 2016;134:229-30.

6. Deramo VA, Meyer $\mathrm{CH}$, Toth CA. Successful macular translocation with temporary scleral infolding using absorbable suture. Retina. 2001;21:304-11.

7. Gaudric A, Massin P, Qinyuan C. An aspirating forceps to remove the posterior hyaloid in the surgery of full-thickness macular holes. Retina. $1996 ; 16: 261-3$

\section{Submit your next manuscript to BioMed Central and we will help you at every step:}

- We accept pre-submission inquiries

- Our selector tool helps you to find the most relevant journal

- We provide round the clock customer support

- Convenient online submission

- Thorough peer review

- Inclusion in PubMed and all major indexing services

- Maximum visibility for your research

Submit your manuscript at www.biomedcentral com/submit 